\title{
The Impact of Language of Learning and Teaching in Primary Schools: A Case Study of the Gauteng Province
}

\author{
Tebogo Mogashoa \\ College of Education University of South Africa \\ Email:mogasti@unisa.ac.za
}

Doi:10.5901/mjss.2014.v5n1p295

Abstract

The aim of the research was to establish the impact of language of learning and teaching in selected South African primary schools. This study was underpinned by critical discourse analysis. The framework of analysis included analysis of texts, interactions and social practices at the local, institutional and societal levels. Language policies can be better understood by looking at the social issues of the community as well as the language and type of texts used. When exercising a choice with regard to method, researchers often have to decide between qualitative and quantitative methods or a combination of both. Qualitative research was chosen as a relevant research instrument for this study to gather information. During data analysis the data were organised categorically and coded and the responses were correlated with the prominent and emerging views identified in the literature survey. The findings of this study revealed that African learners are taught in second or third languages while white learners are taught in their home languages. The Department of Basic Education and policy makers should be persuaded to promote programmes in which home language instruction is given meaningful financial and material support to make the production and rewriting of textbooks and dictionaries across school curricula possible.

Keywords: Curriculum, involvement, teacher, evaluation and assessment, critical discourse analysis, significance, qualitative, perspectives, purpose and emphasis.

\section{Introduction and Context of the Study}

Critics of South African education policies condemned the National Department of Education for a curriculum said to be irrelevant and uninteresting for most South African learners. Before 1994 the education system in South Africa contradicted world trends by deliberately choosing to serve the education needs of only a section of the South African population. The birth of democracy in 1994 led to the establishment of a new dispensation and a concomitant need for the democratisation of the education system. The apartheid education system disadvantaged the majority of South Africans especially the black communities. A new democracy demanded change in many spheres of life in South Africa in particular in education.

Among other reforms proposed by the Government of National Unity (GNU) was transformational outcomes-based education. This ushered Curriculum 2005 with its emphasis on outcomes-based education. According to Kramer (2006: 1), the introduction of outcomes-based education in South African schools and the advent of Curriculum 2005 marked an exciting transformation of the education system. The new curriculum was modelled according to William Spady's version of outcomes-based education, who defined it as a "comprehensive approach to organising and operating an education system that is focused on and defined by the successful demonstrations of learning outcomes sought from each other "(Spady, 1994:1). There was consensus about transforming education in South Africa by different stakeholders in education in order to change the education system and introduce a new curriculum.

The Department of Education has taken a transformative approach to outcomes-based education with emphasis on critical outcomes. Critical outcomes are broad educational goals or a set of skills, attitudes and knowledge that all learners should demonstrate after being exposed to learning and teaching. Curriculum 2005 was also informed by the objectives of the South African Qualifications Authority Act , 1995 (Act 58 of 1995) (RSA,1995 : 1) which were to create an integrated national framework for learning achievements, to enhance the quality of education and training, to accelerate the redress of the past unfair discrimination, training and employment opportunities and thereby contribute to the full personal development of each learner and the social and economic development of the nation at large. The government was actually trying to come up with a new education system which would cater for all its citizens regardless of race, culture, gender, creed or religion. 
In 2000, Curriculum 2005 was reviewed. The review of Curriculum 2005 was due to an outcry that teachers were not coping with the curriculum implementation process. Thus, a Ministerial Committee was established, chaired by Linda Chisholm, which emerged with the Revised National Curriculum Statement (RNCS) (Review Committee on Curriculum 2005, 2000: 21). According to the reviewers of Curriculum 2005, teachers needed to be empowered to become successful curriculum mediators by means of effective training opportunities (Review Committee on Curriculum 2005, 2000: 96). The review committee recommended that strengthening the curriculum required streamlining its design features through an amended National Curriculum Statement. The curriculum documents needed to be simplified and workload reduced. Streamlining Curriculum 2005 was the right step taken by the Education authorities in order to assist the teachers to implement curriculum effectively.

Based on research, management can make intelligent and informed decisions (Moorty 2010:1). It is for that reason that, this research is necessary for education policy makers in realising how teaching and learning is affected by the various education policies such as Language in Education Policy. Policy makers and decision-making bodies may find the findings of this study useful in shaping the education system in future. Language in Education Policy can have a negative impact on teaching and learning if not appropriately implemented. On the other hand, Language in Education Policy can also have an effect on teaching and learning, especially when learners are taught in the language they do not understand. Thus, the teachers' knowledge and understanding of language issues in education policy (LiEP) need to be investigated in order to identify problems teachers and learners might be experiencing in terms of the language of learning and teaching (LoLT), also known as language of instruction. The study has the potential to highlight teachers' opinions, ideas and recommendations in current debates about challenges of interpreting and implementing the various education policies on teaching and learning.

Drotor (2007:3), states that in order to significant, the research needs to exceed the threshold of current scientific work in a specific area. A research study updates previous researches and its development. The significance of the study should discuss the importance of the proposed research and its relevance. The investigation might be relevant for theory, practice and future research. The research study can enhance the critical and analytical thinking of students, since in most of the institutions small research studies are an essential component of the syllabus. The research study can give food for thought to new researchers. This study is also considered to be important in the sense that it could create interest among researchers and teachers to engage in more critical reflection and debate on the implementation of language policies in South African schools. The opinions of teachers are necessary if the Department of Education is to develop strategies and mechanisms to improve the standard of teaching and learning in schools. The teachers are the key role players through which all aspects of education policies pertaining to teaching and learning reach the learners.

\section{Theoretical Frameworks}

This study was underpinned by critical discourse analysis. According to Van Dijk (2006:252), critical discourse analysis is primarily interested in and motivated by the endeavour to understand pressing social issues. Wodak (2009:7) argues that critical discourse analysis emphasises the need for interdisciplinary work in order to gain a proper understanding of how language functions in constituting and transmitting knowledge in organising social institutions. Rogers, MalamcharuvilBerkes, Mosley, Hui and O'Garo Joseph (2005:368) state that critical theories are generally concerned with issues of power and justice and the ways that the economy, race, class, gender, religion, education, and sexual orientation construct, reproduce or transform social systems. The framework of analysis includes analysis of texts, interactions and social practices at the local, institutional and societal levels. Critical discourse analysis deals with long term analysis of fundamental causes and consequences of issues. Therefore, it requires an account of detailed relationships between text, talk, society and culture. Language policies can be better understood by looking at the social issues of the community as well as the language and type of texts used.

McGregor (2010:2) argues that critical discourse analysis challenges us to move from seeing language as abstract to seeing our words as having meaning in a particular historical, social and political condition. Hence critical discourse analysis studies real, and often extended, instances of social interaction which take particularly in linguistic form (Blommaert \& Bulcaen 2000:448).

Critical discourse analysis is primarily positioned in the environment of language and its successes can be measured with a measuring rod of the study of languages. Language can be used to represent speakers' beliefs, positions and ideas in terms of spoken texts like conversations. Written or oral messages convey meanings if we analyse the underlying meaning of the words. Analysis of underlying meanings can assist in interpreting issues, conditions and events in which the teachers and learners find themselves. Using words can direct/assist those in control of the 
education system. Critical discourse analysis can only make a significant and specific contribution to critical social or political analyses if it is able to provide an account of the role of language, language use, discourse or communicative events in the production of dominance and inequality (Van Dijk 2006:279; McGregor 2010:2). The focus of the theory and practice of critical discourse analysis is on structures of texts and talk. Critical discourse analysis tries to determine the relationship between the actual text and the processes involved in listening, speaking, reading and writing. Thus, this provides skills in critically analysing written text, that is, the way we write and what we say. McGregor (2003:2) argues that given the power of the written and spoken word, critical discourse analysis is necessary for describing, interpreting, analysing and critiquing social life reflected in text. Teachers and learners' understanding of the language of learning and teaching is imperative.

According to Fairclough (1995:43), language is a material form of ideology, and language is invested by ideology. Luke (1996:12) argues that critical discourse analysis shares with sociolinguistics and ethnomethodology the assumption that language should be studied in a social context. Discourse is a complex of three elements, namely, social practice, discoursal practice (text production, distribution and consumption), and text, and analysis of a specific discourse calls for analysis in each of these dimensions and their interrelations (Fairclough 1995:74). Critical discourse analysis of written and spoken texts operates in two ways, namely, critically and constructively. Texts are located in key social institutions, that is, families, schools, churches, work places, mass media or government. Human subjects use texts to make sense of their world and to construct social actions and relations in the labour of everyday life while at the same time, texts position and construct individuals, making available various meanings, ideas and versions of the world (Luke 1996:12). In face-to-face events in classrooms, discourse often unfolds in an uneven, contested, and unpredictable social configurations.

In order to guide this research, the problem statement is formulated in a form of a question. According to Andrews (2003:69), the research questions must have the potential for being answered in the project or research study to be undertaken. The main research question is as follows:

$>$ How knowledgeable are teachers and learners in terms of the language of learning and teaching (LoLT)?

\section{Reseach Design and Methods}

When exercising a choice with regard to method, researchers often have to decide between qualitative and quantitative methods or a combination of both. Qualitative research is chosen as a relevant research instrument for this study, as it will enable the researcher to explore and describe the observed phenomenon as understood by the participants from their own frame of reference (Bogdan \& Biklen 2006:146). Yin (2009:5) argues that qualitative research approach investigates typical human phenomenon and tries to understand such human behaviour against natural contexts. The qualitative research process is more holistic and emergent with specific focus design, measurement instrument (e.g. interviews) and interpretations developing and possibly changing along the way of investigation (Leedy \& Ormrod 2005:102). Ethnographers assume interactive social roles whereby they record observation and interviews with participants in a range of contexts (Mc Millan \& Schumacher 2011:372). For these reasons the researcher enters the research field with an open mind and acknowledges that the picture will be constructed as data are collected and examined.

The most appropriate way to understand why individuals behave in a specific manner is to be closely involved in their social interactions. According to Marshall and Rossman (2010:68) qualitative research approach permits this to happen because the researcher is able to reconstruct the lived experiences of the subjects. Such results are not arrived at through statistical procedures, but through the understanding of quality human behaviour (De Vos 2005:240). Leedy (2006:88) indicates that the research methodology to be adopted for a particular problem must always recognise the nature of the data that will be amassed in the resolution of the problem. This means that the nature of the problem is the determinant of the research method to be employed, and not the other way round.

According to McMillan and Schumacher (2011:401), qualitative research uses small samples of people nested in their context and studied in depth. Hoberg (1999:58) states that generally in qualitative research a small distinct group of participants will be investigated to enable the researcher to understand the problem in depth. To this effect, Neuman (2009:376) maintains that since the researchers are privileged to access intimate information from subjects, they therefore have a moral obligation to uphold confidential information, which may include disguising members' names or their places in the field notes. In this study a meeting with the principals of the selected schools was held, they were requested to arrange staff meetings in their schools and to invite the researcher to explain the purpose and benefits of the research. Thus, the researcher informed the participants about the purpose of the research. 
This deliberate selection which Patton (2002:169) refers to as purposeful sampling, is a process of selecting information rich cases for study-in-depth of the topic under investigation. In this study the participants are seen as individuals who "possess special knowledge, status or communication skills" and who are willing to share this with the interviewer (Le Compte \& Preissle (1993:166). As the researcher was familiar with the officials of the Department of Education, principals of schools, HOD's and teachers, it was unnecessary to make use of a gate-keeper. The focus groups included Grade 4 and 6 teachers and learners. These key-informants were selected based on the researcher's knowledge of the selected district. Schools selected were situated in different areas, namely, informal settlement, township, farm and urban areas.

The researcher secured permission from the Gauteng Department of Education as well as the schools concerned. Focus group interviews build on the notion that the group interaction encourages respondents to explore and clarify individual and shared perspectives (Tong, Sainbury \& Craig 2007:3). They depend on dynamic interaction to provide the information sought (McLafferty 2006:2). Strydom (2002:307) states that focus groups draw on three of the fundamental strengths, namely, exploratory and discovery, context and depth interpretation. When participants are stimulated to discuss, the group dynamics can generate new thinking about the topic which will result in a much more in-depth discussion. It provides rich data through direct interaction between researcher and participants. People are able to build on others' responses and come up with ideas they might not have thought of in a one on one interview. They are very cost effective in terms of gathering primary data and are very much time efficient. However, it is sometimes difficult to have the participants share their real feelings towards some sensitive topics publicly, this can in turn influence the output data.

\section{Data Analysis}

In this study throughout the data analysis process the data were coded using as many categories as possible. The purpose was to identify and describe patterns and themes from the perspective of the participants and an attempt be made to understand and explain these patterns and themes. During data analysis the data were organised categorically and coded and the responses were correlated with the prominent and emerging views identified in the literature survey. This process involves grouping of information, coding information of similar kind and genre and describing the information by inductive reasoning. After the major topics and subtopics that emerged from interviews and document analyses had been identified, the data collected were arranged and categorised according to topics and subtopics. From these, categories and patterns that evolved language issues were identified, labelled and interpreted.

According to Bazely (2009:3) there are various strategies and stages of data analysis such as organising data, pulling apart (discovery and coding), putting together (reconstructing, interpreting and theorising), writing and assessing the quality of data. Organising data includes many aspects, namely, gathering together and organising, making of working copies of the whole set, filing away one whole set to save as clean copies, revisiting own positioning, revisiting purpose and research question, listing theoretical questions and listing specific questions. Pulling together involves reading the entire data set several times, checking at what stands out, trying a key word process, listing possible codes, ideas and hunches, giving each coding segment an abbreviation for easy use during subsequent analysis, broadly assigning portions of the data to codes, and checking at what is left uncoded. Putting together includes typologies, data tables, matrices, displays, timelines, card sorts, determining how emerging patterns relate to one another, developing concepts and theoretical propositions grounded in the data, creating metaphors for thinking about the data, creating visuals to represent relationships as well as reading literature again. Writing strategy involves memos to explain categories, summaries of interviews, context description and participant description. Silverman (2006:7) state that in assessing the quality of data the researcher should check whether the data was soliindicated or unsoliindicated, consider observer's influence on setting, whether there are multiple sources of data and whether the data are rich with detail and description.

Patton (2002:381) states that content analysis is the process of identifying, coding and categorising the primary patterns in the data. In this study transcripts were analysed in order to establish how knowledgeable were teachers and learners in terms of the language of teaching and learning. Tape recordings were listened to and transcripts read over and over. After tape recordings were transcribed, the researcher started by looking for any interesting patterns, whether anything conspicuous stood out as interesting or puzzling.

\section{Research Findings and Discussions}




\subsection{Interviews with teachers}

\subsubsection{Question: What is the language of learning and teaching in this school?}

At the five schools selected, four schools use English as the language of learning and teaching, only one school uses parallel medium, which is English and Afrikaans. To help to determine why that particular language or languages were preferred as language/s of teaching and learning, the following question was asked:

\subsubsection{Question: Why is this language preferred to be the language of learning and teaching in this school?}

Twenty (20) teachers who were interviewed indicated that English is preferred because most learning and teaching support materials in almost all learning areas are in English and Afrikaans but not in African languages. At the school where parallel medium is used, four teachers indicated that African learners speak different African languages at home and other learners speak either Afrikaans or English at home. Hence African learners are taught in English while Afrikaans learners are taught in Afrikaans. Below are some of the responses from the teachers:

Teacher $\mathrm{E}$, "The text books are written in English or Afrikaans."

Teacher I, "Learners speak different languages at home."

Teacher C, "Afrikaans speaking learners are taught in Afrikaans."

To establish the mostly spoken language in these schools, the following question was asked:

\subsubsection{Question: Which language is mostly spoken in this school?}

Twenty (20) teachers indicated that at all the schools selected for this study, the language most often spoken is Sepedi. The next question sought to establish the knowledge teachers and learners have with regard to the language they preferred to use as language of learning and teaching.

\subsubsection{Question: How knowledgeable are the teachers and the learners with regard to the language of learning and} teaching in this school?

The common response to this question was that the teachers have a fair knowledge of English but the learners struggle, especially in those schools where English is the only language of learning and teaching. Teacher I explained, "Learners actually do not grasp the language. They also do not feel comfortable in answering questions when asked to respond in English. They are really struggling." Teacher F added, "The learners do not understand instructions when asked in English". Teacher L said, "We always explain in the learners' home language so that they can understand what is expected of them." To help determine the impact the language of learning and teaching has for learning, the following question was asked:

\subsubsection{Question: What impact does the language of learning and teaching in this school have in terms of learning and teaching?}

The consensus was that the language of learning and teaching has a negative impact on teaching and learning since most do not understand English. Those who are taught in Afrikaans do not struggle with their learning activities. This was echoed by one of the participants (Teacher J) who said, "Very, very bad. You know, I gave grade 6 learners some books which I think are of grade 3 level, but some of the learners could not read at all." This view was supported by Teacher $\mathrm{H}$ who said, "For the Afrikaans learners it is easy because they speak Afrikaans at home."

\subsection{Interviews with learners}

\subsubsection{Question: What language do you speak at home?}

Twenty-five (25) learners participated in this study. In responding to the above question, 15 learners indicated that their home language is Sepedi. Furthermore, five learners said their home language is IsiNdebele while three said Afrikaans. Only two mentioned English as their home language. The following were some of the verbatim responses to the question 
above:

Learner X said, "I speak Sepedi."

Learner F said, "I speak IsiNdebele."

Learner T said, "I speak Afrikaans."

Learner C said, "I speak English."

\subsubsection{Question: In which language are most of the learning areas/subjects being taught in your school?}

Twenty (20) learners in schools B, C, D and E mentioned that all learning areas/subjects are taught in English. It was only in school A where the five learners indicated that some are taught in English while others are taught in Afrikaans. The following were some of the verbatim responses to the question above:

Learner F said, "We are taught in English."

Learner J said, "We are taught in English and other learners are taught in Afrikaans."

\subsubsection{Question: How well do you understand this language?}

In responding to the question above, 16 learners in the four schools where English is the language of learning and teaching complained that they did not understand the language; only four understood the language. The learners in the dual medium school did not have any problems with the languages they are taught in. The following were some of the verbatim responses to the question above:

Learner Y said, "I don't understand English well."

Learner J said, "I understand Afrikaans well."

Learner A said, "I understand English well."

\subsubsection{Question: What impact does this language have on your learning?}

Sixteen (16) learners in the four schools which use English as the language of learning and teaching indicated that they struggle to understand what their teachers are teaching them and as such the teachers had to explain in the learners' home languages. The learners who are taught in Afrikaans or English did not have any difficulties in learning. The following were some of the verbatim responses to the question above:

Learner B said, "I don't understand English well and this causes me to fail some learning areas."

Learner W said, "I understand what my teachers teach me because I understand English well."

The above section indicated the knowledge learners have in terms of the language of learning and teaching and how it impacted on their learning.

\section{Conclusions and Recommendations}

The findings of this study revealed that African learners are taught in second or third languages while white learners are taught in their home languages. The researcher concedes that learners learn more easily when taught in their home languages. It is recommended that learners be given the opportunity to learn in their dominant home languages if at all possible. Studies have shown the value of home language instruction for ultimate literacy and academic achievement. According to research findings, the home language is the most appropriate medium for imparting the skills of reading and writing, particularly in the initial years of schooling (de Wet 2007:1). Learning in one's language holds a number of advantages. It improves academic performance and access to education and reduces repetition and drop-out rates.

The researcher recommends that in case teachers are not able to teach learners in their home language, they should communicate with learners in that language of teaching and learning at all times so that learners are able to practise speaking that language that they are taught in. Teachers should always give instructions in simple language at the level of the learners. Learners should be engaged in learning activities such as debates and role play and be encouraged to speak in the language of learning and teaching. The researcher further recommends that teachers should use big books with pictures that relate to the story during reading lessons.

According to Department of Education (2010:29), teacher training and development programmes should include issues related to language. The Language in Education Policy (LiEP) and curriculum should be streamlined to promote a common purpose and emphasis. The policy on African languages should be stated with greater clarity. In the Foundation 
Phase, learning and teaching support materials should be made available in all languages.

The Department of Basic Education and policy makers should be persuaded to promote programmes in which home language instruction is given meaningful financial and material support to make the production and rewriting of textbooks and dictionaries across school curricula possible. Educators should be educated on the implications and effects of different language policies. It is also imperative to establish in-service training programmes that will feature, inter alia, topics on the role of code switching, since it was observed in this study that code switching is an important content transmission and classroom management resource.

Learners should be given opportunities to talk and write about previous experiences, individual or group reading of fiction or non-fiction texts, book talks, learner-dictated stories and texts, collaborative and process writing, as well as working on personal word lists (Marungudzi 2009:29). Children learn language when they actually use it to think and communicate in meaningful situations. Teachers should promote an environment favourable to second language development. Learners should be provided with opportunities to actively construct meaning from the language input they receive from others. Strategies may include body language, visuals and manipulatives in learning activities as well as introducing and formally teaching new vocabulary words. When introducing new words, it is imperative to clearly and effectively convey meaning to the learners, and then, to check for their understanding. Learners should be taught techniques of asking and answering oral questions as well as to participate in classroom discussions, oral presentations and writing reports. Learners should be given guidelines and exercises on the use of dictionaries.

\section{References}

Andrews, R. 2003. Research questions. London: Continuum.

Bazeley, P. 2009. Analysing Qualitative Data: More than identifying Themes. Melbourne Australian Catholic University.

Blommaert, J \& Bulcaen, C. 2000. Critical Discourse Analysis. Annual Reviews Publishers. Vol. 29: 447-466.

Bogdan, R.C \& Biklen, S.K. 2006. Qualitative research for education: An introduction to theory and methods (5th edition). Boston: Allyn \& Bacon.

Department of Education. 2010. The status of language of learning and teaching (LoLT) in schools: A quantitative overview. Pretoria: Government Printers.

De Vos, A.S. 2005. Combined quantitative and qualitative approach. In De Vos, A.S. (eds). Research at grassroots: For the social sciences and human science professions. 3rd edition. Pretoria: Van Schaik.

Drotor, D. 2007. Thoughts on Establishing Research Significance and Preserving Scientific Integrity. Oxford Journals. Vol. 33:1-5.

De Wet, C. 2007. Factors influencing the choice of English as language of learning and teaching (LoLT): A South African perspective. South African Journal of Education. Vol. 28: 178-191.

Fairclough, N. 1995. Critical Discourse Analysis: the critical study of language. London and New York. Longman.

Kramer, D. 2006. OBE teaching toolkit: OBE strategies, tools and techniques for implementing C2005. Cape Town. ABC Books.

Le Compte, M.D. \& Preissle, J. 1993. Ethnography and qualitative design in education research. $2^{\text {nd }}$ edition. San Diego, CA: Academic Press.

Leedy, P.D. \& Ormrod J.E. 2005. Practical research planning and designing (3rd edition). Upper Saddle: Merril Prentice-Hall.

Lucke, A. 1996. Text and Discourse Analysis. New York: American Educational Research Association. Vol. 21:3-17.

Marshall, C. and Rossman, G.B. 2010. Designing qualitative research. Thousand Oaks, CA: Sage Publications.

Marungudzi, T. 2009. English as language of learning and teaching: Perspectives of secondary school teachers in the Masvingo District (Zimbabwe). Pretoria. Unisa.

Mc Gregor, S.L.T. 2010. Critical Discourse Analysis: A Primer. Halifax. Mount Saint Vincent University

McLaffery, I, 2006. Focus group interview as a data collecting strategy. Dandee City. University of Dandee.

McMillan, J.H. \& Schumacher, S. 2011. Research in education: A conceptual introduction. $5^{\text {th }}$ edition. New York: Haper Collins.

Moorty, S. 2010. The Significance of research in Business Decision Making. Thousand Oaks, CA: Sage.

Neuman, W.L. 2009. Social research methods: Qualitative and Quantitative approaches (7th edition) Boston: Allyn \& Bacon.

Patton, Q.M. 2002. Qualitative evaluation and research methods (3rd edition) Newbury Park: Sage Publications.

Rogers, R., Malamcharuvil-Berkes, E., Mosley, M., Hui, D and O' Garro Joseph, G. 2005. Critical Discourse Analysis in Education: A Review of the Literature. Washington. Sage Publications.

Silverman, D. 2006. Interpreting Qualitative Data 3rd Edition. Thousand Oaks. Corwin Press.

Spady, W.G. 1994. Outcomes-based education, critical issues and answers. Virginia: American Association of School Administrators.

Strydom, H. 2002. Participatory action research- In De Vos, A.S. (eds). Research at grassroots: For the social sciences and human science professions. $2^{\text {nd }}$ edition. Pretoria: Van Schaik.

Tong, A; Sainsbury, P \& Craig, J. 2007. Consolidated criteria for reporting qualitative research: A 32 item checklist for interviews and focus groups. New South Wales. University of Sidney.

Van Dijk, T.A. 2006. Principles of Critical Discourse Analysis. Amsterdam. University of Amsterdam.

Wodak, R \& Meyer, M. 2009. Methods of Critical Discourse Analysis. London and New York. Longman. 
